\title{
Simulation of Actual Evapotranspiration and Evaluation of Three Complementary Relationships in the Upper Regions of the Mekong River and the Salween River
}

\section{Yongshan Jiang ( $\nabla$ jiangys.19s@igsnrr.ac.cn )}

Institute of Geographic Sciences and Natural Resources Research CAS: Institute of Geographic Sciences and Natural Resources Research Chinese Academy of Sciences

Zhaofei Liu

Institute of Geographic Sciences and Natural Resources Research, Chinese Academy of Sciences

\section{Rui Wang}

Institute of Geographic Sciences and Natural Resources Research, Chinese Academy of Sciences Pingcuo Gele

The Tibet Autonomous Region Hydrology and Water Resources Survey

\section{Research Article}

Keywords: complementary relationship method, generalized complementary relationship, hydrological budget balance, actual evapotranspiration

Posted Date: July 13th, 2021

DOl: https://doi.org/10.21203/rs.3.rs-655938/v1

License: (c) (1) This work is licensed under a Creative Commons Attribution 4.0 International License.

Read Full License 

in the upper regions of the Mekong River and the Salween River

$5 \quad{ }^{1}$ Institute of Geographic Sciences and Natural Resources Research, Chinese Academy of Sciences, 100101, Beijing,

${ }^{2}$ College of Resources and Environment, University of Chinese Academy of Sciences, Beijing 10100049 , China 


\section{Funding}

18 This work was supported and funded by the Strategic Priority Research Program of the Chinese Academy of Sciences

19 (XDA2006020202; XDA23090302) and National Natural Science Foundation of China (41571027).

\section{Conflicts of interest}

21 The manuscript has not been published before and is not being considered for publication elsewhere. We declare that we

22 do not have any commercial or associative interest that represents a conflict of interest in connection with the work 23 submitted.

\section{Availability of data and material}

25 The data, materials and codes of this article can be obtained by contacting the authors at 18811576709@163.com and 26 zfliu@igsnrr.ac.cn.

\section{Code availability}

28 Not applicable.

\section{Authors' contributions}

30 Yongshan Jiang and Zhaofei Liu contributed to the conception of the study; Yongshan Jiang, Zhaofei Liu, and Rui Wang

31 contributed significantly to analysis and manuscript preparation; Pingcuo Gele provided observed data; Yongshan Jiang 32 performed the data analyses and wrote the manuscript; Zhaofei Liu helped perform the analysis with constructive 33 discussions. 


\section{$34 \quad$ Ethics approval}

35 Not applicable.

\section{Consent to participate}

$37 \quad$ Not applicable.

\section{Consent for publication}

39 Written informed consent for publication was obtained from all participants.

40 
41 Abstract: Based on observed precipitation and runoff data, monthly actual evapotranspiration $\left(\mathrm{ET}_{\mathrm{a}}\right)$ was calculated by the 42 hydrological budget balance method in the Nu River Basin (NRB) and Lancang River Basin (LCRB). The performance 43 of three developed complementary relationship methods, the nonlinear advection-aridity (nonlinear AA) method, 44 generalized complementary relationship method (B2015), and sigmoid generalized complementary function (H2018), on 45 simulating $\mathrm{ET}_{\mathrm{a}}$ were evaluated. The evaluation results showed that three methods were able to accurately simulate 46 monthly $\mathrm{ET}_{\mathrm{a}}$ series. The NSE between the monthly $\mathrm{ET}_{\mathrm{a}}$ simulated by the nonlinear AA, B2015, and H2018 methods 47 and the water-balance-derived $\mathrm{ET}_{\mathrm{a}}$ were $0.89,0.83$, and 0.91 , respectively. The R-square were $0.90,0.84$, and 0.93 , 48 respectively. Overall, the H2018 method showed the best performance. The parameter $\alpha$ had a negative correlation with 49 regional aridity index. Annual $\mathrm{ET}_{\mathrm{a}}$ and precipitation showed significant increasing trends during 1956-2018 in the basins 50 at all temporal scales (dry and wet seasons and annual series). Runoff also exhibited an increasing trend in each sub-basin, 51 except for the downstream region of the LCRB. The increasing magnitudes of wet reason precipitation and runoff in the 52 mid-stream region was the highest, with the value of $73.7 \mathrm{~mm} / 10 \mathrm{a}$ and $44.9 \mathrm{~mm} / 10 \mathrm{a}$, respectively. The $\mathrm{ET}_{\mathrm{a}}$ increased 53 dramatically in the downstream region, the magnitude reached $25.9 \mathrm{~mm} / 10$ a. Precipitation was the main factor leasing to $54 \mathrm{ET}_{\mathrm{a}}$ change. The increasing magnitude of $\mathrm{ET}_{\mathrm{a}}$ accounted for $42.4 \%$ of the precipitation increment. Research on the 55 influence mechanism between meteorological factors and $\mathrm{ET}_{\mathrm{a}}$ showed that the contribution rate of air temperature to $56 \mathrm{ET}_{\mathrm{a}}$ was the highest, reaching 23.5\%, which showed a significant positive correlation. The second was wind speed, whose 57 contribution rate was $-10.2 \%$ on average, and even reached $-14.1 \%$ in the upstream region of the NRB. The correlation 58 coefficient between $\mathrm{ET}_{\mathrm{a}}$ and wind speed was highest in mid-stream region of the NRB, which was greater than 0.80 . The 59 contribution rates of increasing humidity to $\mathrm{ET}_{\mathrm{a}}$ were $-12.5 \%$ and $-9.2 \%$ in the NRB and LCRB, respectively. $\mathrm{ET}_{\mathrm{a}}$ was 60 negatively correlated with humidity. The negative correlation was especially strong in the mid-stream region, with 61 coefficients were greater than -0.65 . The sunshine hours had the least effect on $\mathrm{ET}_{\mathrm{a}}$, and the contribution rates were $-6.5 \%$ 62 and $-4.1 \%$, respectively.

63 Keywords: complementary relationship method; generalized complementary relationship; hydrological budget balance;

64 actual evapotranspiration

65 


\section{Introduction}

67 Actual evapotranspiration $\left(\mathrm{ET}_{\mathrm{a}}\right.$ ) plays a crucial role in the global water and energy cycles. $\mathrm{ET}_{\mathrm{a}}$ and runoff account for

$6859 \%$ and $41 \%$ of land surface precipitation, respectively (Oki and Kanae 2006). And the solar radiation energy absorbed

69 by land surface exceeds $50 \%$ is used for $\mathrm{ET}_{\mathrm{a}}$ (Trenberth et al. 2009). ET $\mathrm{T}_{\mathrm{a}}$ can reflect the regional changes of land surface

70 energy and hydrological budgets. Analyses of trends of $\mathrm{ET}_{\mathrm{a}}$ are greatly significant for understanding climate change and

71 its impacts at regional scales. Accurate simulation of $\mathrm{ET}_{\mathrm{a}}$ is crucial for the management and planning of water resources,

72 forestry, and agricultural irrigation (Maes et al. 2012; Farahani et al. 2007; Fisher et al. 2017).

73 Obtaining $\mathrm{ET}_{\mathrm{a}}$ is a challenging task because of its complex interactions across the soil-plant-atmosphere continuum

74 (Katul et al. 2012). ET $_{\mathrm{a}}$ can be accurately monitored by a wide variety of ground measurements such as lysimeters, energy

75 balance Bowen ratio, and eddy covariance (Allen et al. 2011). However, estimation of large-scale, long-term ET remains

76 difficult since these techniques typically cover short periods with limited spatial extent (Ma and Szilagyi 2019). And most

$77 \mathrm{ET}_{\mathrm{a}}$ methods require a significant number of soil and vegetation-related parameters as inputs (Masson et al. 2003), thus

78 leading to data complexity and additional uncertainties.

79 There are several methods can estimate $\mathrm{ET}_{\mathrm{a}}$ by using only routine meteorological observations data (Chen et al. 2020;

80 Fan et al. 2018; McMahon et al. 2013). Among them, Bouchet (1963) proposed a complementary relationship (CR) which

81 had been proven to be a feasible and efficient approach (Xu and Singh 2005; Nakamichi and Moroizumi 2015; Hobbins

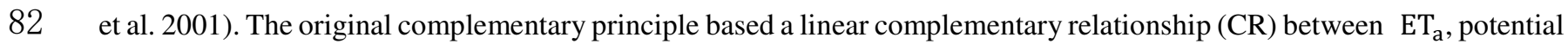

83 evapotranspiration $\left(\mathrm{ET}_{\mathrm{p}}\right)$, and wet environment evapotranspiration $\left(\mathrm{ET}_{\mathrm{w}}\right)$, in which $\mathrm{ET}_{\mathrm{a}}$ and $\mathrm{ET}_{\mathrm{p}}$ depart from $\mathrm{ET}_{\mathrm{w}}$ in

84 opposite directions when the land surface is drying from completely wet conditions with a constant energy input (Brutsaert

85 2015; Zhou et al. 2020). Several methods based on the CR had been proposed such as Advection-Aridity (Brutsaert and

86 Strick 1979), CRAE (Morton 1983), and Granger-Gray (Granger and Gray 1989) methods. And they had been extensively

87 used for obtaining long-term regional $\mathrm{ET}_{\mathrm{a}}$ (Jian et al. 2018; Szilagyi et al. 2009).

88 However, in recent years, many studies had shown that it was difficult for $\mathrm{ET}_{\mathrm{a}}$ and $\mathrm{ET}_{\mathrm{p}}$ to satisfy the completely 89 symmetrical complementary relationship. Brutsaert (2015) formulated a more general and nonlinear version of the 90 complementary relationship which defined as "the generalized complementary relationship" by generalizing the CR to a 
91 fourth-order polynomial function between $E T_{a} / E_{P e n}$ and $E T_{w} / E_{P e n}$. Among them, $E_{P e n}$ is calculated by the Penman 92 (1948) equation, which is the sum of radiation $\left(E_{\text {rad }}\right)$ and aerodynamic $\left(E_{\text {aero }}\right)$. Han et al. (2018) combing a sigmoid form 93 of the generalized complementary function into the traditional AA method to represent the relationship between $\mathrm{ET}_{\mathrm{a}}$ and $94 \mathrm{ET}_{\mathrm{p}}$ by considering boundary conditions for extremely arid and completely wet environments. This method also 95 developed minimum $\left(\mathrm{x}_{\min }\right)$ and maximum $\left(\mathrm{x}_{\mathrm{max}}\right)$ limits to $E_{r a d} / E_{P e n}$. Szilagyi et al. (2017) proposed a calibration-free 96 nonlinear CR method with more appropriate physical constraints which built on the latest researches of the nonlinear 97 formulation by Brutsaert (2015) and Crago et al. (2016). The most prominent advantage in the method is that it determines 98 the parameter of the Priestley-Taylor coefficient (Priestley and Taylor 1972) from temperature and humidity data over wet 99 areas. Therefore, the method avoids the complex parameter calibration requiring prior information of "ground-truth" $\mathrm{ET}_{\mathrm{a}}$ 100 which is often missing in developing countries, including China.

101 The Mekong River and the Salween River are two important international rivers in Southeast Asia. The Mekong River 102 provides renewable energy and food security for a population of more than 60 million people in six countries: China, 103 Myanmar, Lao PDR, Thailand, Vietnam, and Cambodia (Sabo et al. 2017). Their water fluctuation could not only affect 104 the water availability, the ecological environment, and food security but also pose enormous challenges to transboundary 105 water utilization and allocation (Fan and He 2015). Therefore, the research on trends of hydrological variables in the basins 106 have attracted extensive attention. In addition, as the upper reaches of Mekong River and Salween River respectively, the 107 Lancang River and Nu River have unique dry-hot valley with great slope and extremely complex terrain. Estimation of 108 the $\mathrm{ET}_{\mathrm{a}}$ change characteristics in the LCRB and NRB would provide certain technical support for water resources 109 management and ecological environment protection in the Mekong River and Salween River basins.

110 A wide range of studies have investigated the spatiotemporal pattern of $\mathrm{ET}_{\mathrm{a}}$ at regional scales (Gao et al. 2007; Liu et al. 111 2019; $\mathrm{Xu}$ et al. 2021; Yang et al. 2021). $\mathrm{ET}_{\mathrm{a}}$ complementary methods have been greatly developed in recent years. 112 However, there are relatively few studies on $\mathrm{ET}_{\mathrm{a}}$ changes and evaluation of the developed CR methods in Mekong River 113 and Sarwen River Basins. In this study, we aimed to (1) simulating $\mathrm{ET}_{\mathrm{a}}$ by the corrected hydrologic budget balance 114 method; (2) evaluating the accuracy of three developed CR methods in simulating monthly $\mathrm{ET}_{\mathrm{a}}$ at regional scales of the 115 two basins; (3) detecting trends of $\mathrm{ET}_{\mathrm{a}}$ in the NRB and LCRB during the past six decades (1956-2018), and quantifying 116 contribution of climate factors to regional $\mathrm{ET}_{\mathrm{a}}$ changes. 


\section{Materials and Methods}

\subsection{Study Area}

119 The Lancang River and Nu River are the upper reaches of the Mekong and Salween rivers which are located in southern

120 Tibet, China. The Nu River basin (NRB) and Lancang River basin (LCRB) are characterized by its location in a deep V-

121 shaped and valley area. In addition, there is a huge drop in water levels between the upper and lower reaches of the river.

122 Because the drop is more than $4,600 \mathrm{~m}$ within the channel length about 2,000 $\mathrm{km}$. Therefore, the time of runoff

123 concentration of the basin is short and the velocity of streamflow is high. This would have a great impact on regional $\mathrm{ET}_{\mathrm{a}}$.

124 The climate in the basins varied significantly from northwest to the southeast due to impacts of topography and latitude.

125 The upstream region belongs to a plateau climate. The climate is cold with little precipitation. The runoff in the upper

126 reaches of the river is mainly recharge by groundwater, accounting for more than $50 \%$ of the annual runoff, followed by

127 recharge by rainwater and meltwater. The mid-stream and downstream regions are located in the subtropical and tropical

128 climate zone. The rainfall is abundant affected by monsoon. The river runoff is mainly replenished by precipitation, which

129 accounts for more than $60 \%$ of the annual runoff. The annual precipitation of LCRB is about $1000 \mathrm{~mm}$ and the temperature

130 is between $14^{\circ} \mathrm{C}$ and $22^{\circ} \mathrm{C}$. The annual precipitation of NRB is about $900 \mathrm{~mm}$ and the annual temperature is between

$13117^{\circ} \mathrm{C}$ to $29^{\circ} \mathrm{C}$. About $85 \%$ of the precipitation is concentrated in the wet season between June and September. The mid-

132 stream is the main rainstorm region in the basin. The mean annual $\mathrm{ET}_{\mathrm{a}}$ in the NRB and LCRB are $350 \mathrm{~mm}$ and $480 \mathrm{~mm}$

133 whilst the mean annual $\mathrm{ET}_{\mathrm{p}}$ are $950 \mathrm{~mm}$ and $1100 \mathrm{~mm}$, respectively. The ratio of $\mathrm{ET}_{\mathrm{a}}$ was $40 \%$ of $\mathrm{ET}_{\mathrm{p}}$ in the basins.

134 The wet season $\mathrm{ET}_{\mathrm{a}}$ accounts for $85 \%$ of the annual $\mathrm{ET}_{\mathrm{a}}$. 


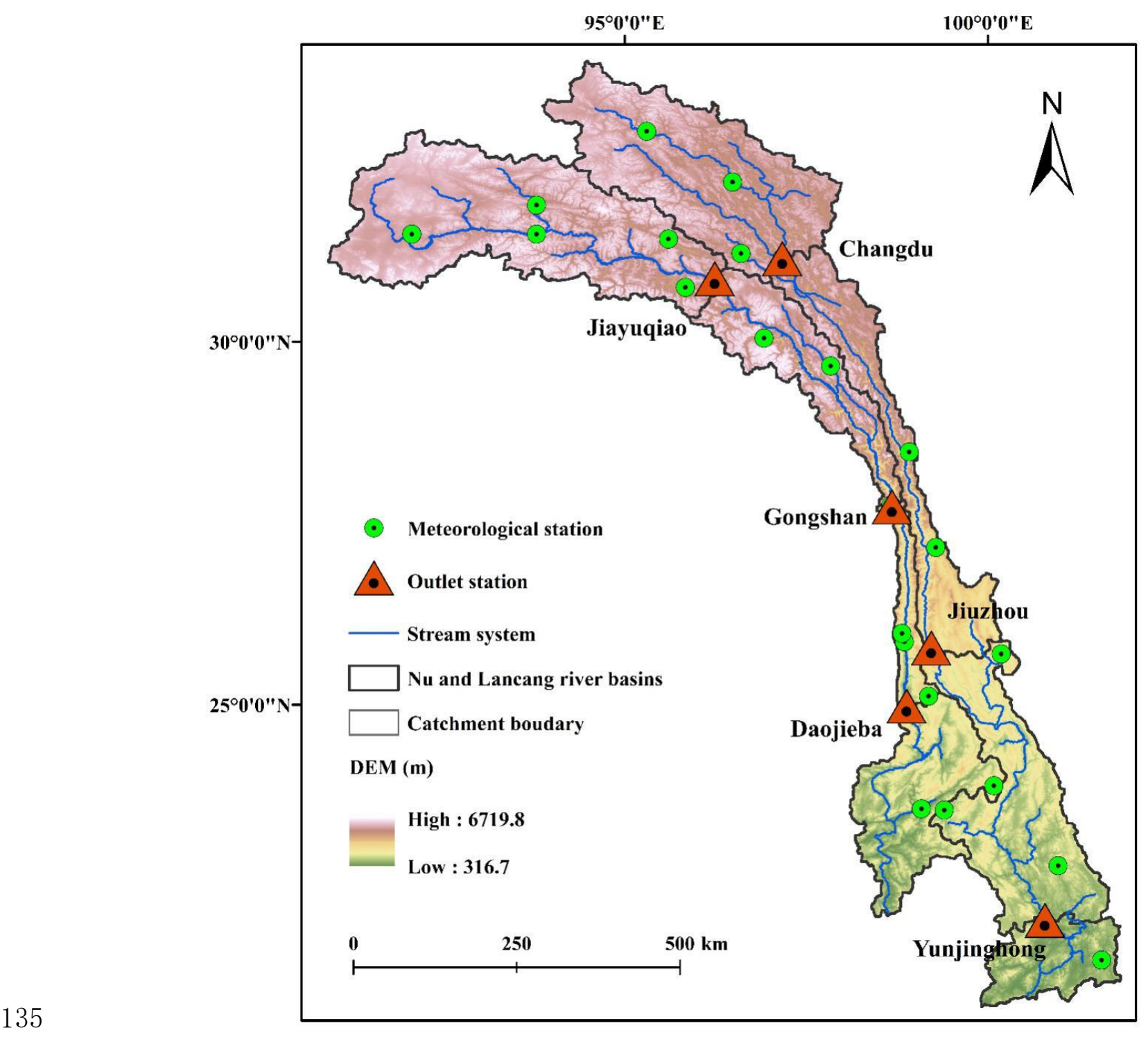

Fig.1 Locations of the Nu River Basin and Lancang River Basin.

\section{$137 \quad 2.2$ Data}

\section{8 (1) Observed meteorological data}

139 Observed daily meteorological data for the period from 1956 to 2018 at 18 stations in and near the study area were obtained

140 from the China Meteorological Administration (http://data.cma.cn/). The data includes precipitation, air temperature, wind

141 speed, relative humidity, and sunshine hours. The monthly and annual series were calculated from the daily observed data 
142 series. The area weight of each station was used to calculate the regional average value. The area weights were calculated 143 based on the Tyson polygon method.

\section{4 (2) Observed hydrological data}

145 Observed runoff data series from six hydrological stations on the main stream of the Lancang River and Nu River were 146 used in this study. Each hydrological station represents the upstream, mid-stream and downstream regions of the LCRB 147 and NRB, respectively (Fig.1). The upstream, mid-stream and downstream regions of the LCRB are described as Changdu 148 (LC-U), Changdu-Jiuzhou (LC-M), Jiuzhou-Yunjinghong (LC-D), respectively. The upstream, mid-stream and 149 downstream regions of the NRB are described as Jiayuqiao (N-U), Jiayuqiao-Gongshan (N-M), Gongshan-Daojieba (N-

150 D), respectively. All sites included monthly runoff data from 1956 to 2000. In addition, Jiayuqiao and Changdu stations 151 also included monthly runoff data from 2007 to 2018. Data were obtained from the Tibet Autonomous Region Hydrology 152 and Water Resources Survey and China Hydrological Yearbook.

\section{$153 \quad 2.3$ Simulation of $\mathbf{E T}_{\mathbf{a}}$}

\section{$154 \quad$ 2.3.1 Hydrological budget balance method}

$155 \mathrm{ET}_{\mathrm{a}}$ of the NRB and LCRB was simulated by the hydrological budget balance method at basin scales (Liu et al. 2014; 156 2019; Wan et al. 2015). In a basin, the hydrological budget balance equation could be expressed as:

$$
E T_{i}^{W B}=P_{i}-R_{i}-\Delta W
$$

where $P$ and $R$ are the basin-wide totals of precipitation $(\mathrm{mm})$ and the net stream flow at the basin outlet $(\mathrm{mm})$,

158 respectively, $\Delta W$ is the change in terrestrial water storage including the surface, subsurface, and ground water changes 159 (mm) at a monthly or annual scale.

160 At the simulation of monthly $\mathrm{ET}_{\mathrm{a}}, \Delta W$ is usually negligible in many studies, which assumes precipitation (evaporation)

161 is the only source (loss) of water in the basin (Hobbins et al., 2001; Zhang et al., 2012). However, the hydrological budget

162 balance may not close when $\Delta \mathrm{W}$ is neglected under changing climate and anthropogenic interferences such as water 163 diversion, reservoir regulation, and agricultural irrigation (Liu et al., 2016). In this study, we defined $(P-R)$ as the biased 
$164 E T_{\text {biased }}^{W B}$ relative to the reference $E T^{W B}$. The $E T_{\text {biased }}^{W B}$ can be corrected based on $E T^{W B}$ measured during the same 165 period at the monthly scale through a two-step bias correction method (BCM, Li et al., 2014). Firstly, at each basin, the 166 monthly $E T^{W B}$ and $E T_{\text {biased }}^{W B}$ series were fitted separately using a gamma distribution. This has been shown as an

167 effective method for modeling the probability distribution of $\mathrm{ET}_{\mathrm{a}}$ (Liu et al., 2016).

168 Water-balance-derived $\mathrm{ET}_{\mathrm{a}}$ was used for trends detection of $\mathrm{ET}_{\mathrm{a}}$ in the NRB and LCRB during 1956- 2018 by Mann-

169 Kendall test in seasonal and annual time series.

\subsubsection{Nonlinear AA method}

171 Brutsaert and Strick (1979) proposed the AA method,

$$
E T_{a}^{A A}=2 E T_{w}-E T_{p}
$$

172 Kahler and Brutsaert (2006) pointed out that the assumed symmetric nature of the CR becomes asymmetric when used

173 with evaporation pan data. This meant that the change in the apparent potential evaporation, as the environment dries from 174 an initially wet condition, will be larger than the corresponding change in $\mathrm{ET}_{\mathrm{a}}$. Therefore, the AA method had since 175 evolved to adopt the asymmetric CR (Brutsaert and Parlange 1998; Szilagyi 2007).

$$
E T_{p}-E T_{w}=b\left(E T_{w}-E T_{a}\right)
$$

176 where b is another constant of proportionality. Rearrangement of (3) leads to

$$
E T_{a}=\frac{1+b}{b} E T_{w}-\frac{1}{b} E T_{p}
$$

177 In nonlinear AA method, $E T_{p}$ and $E T_{w}$ are denoted by the Penman (1948) equation $\left(E_{P e n}\right)$ and the Priestley-Taylor 178 (1972) equation, respectively.

$$
\begin{gathered}
E T_{w}=\alpha E_{\text {rad }}=\alpha \frac{\Delta}{\Delta+\gamma}\left(R_{n}-G\right) \\
E_{\text {Pen }}=E_{\text {rad }}+E_{\text {aero }}=\frac{\Delta}{\Delta+\gamma}\left(R_{n}-G\right)+\frac{\gamma}{\Delta+\gamma} f\left(u_{z}\right)\left(e_{s}-e_{a}\right)
\end{gathered}
$$

179 Normalized by $E_{P e n}$, the nonlinear AA method can be expressed as a linear function (Han et al. 2008):

$$
\frac{E T_{a}^{A A}}{E_{\text {Pen }}}=\left(1+\frac{1}{b}\right) \alpha \frac{E_{\text {rad }}}{E_{\text {Pen }}}-\frac{1}{b}
$$

where $E_{\text {rad }}$ and $E_{\text {aero }}$ are the radiation and aerodynamic terms for the Penman equation, respectively (mm/day); $\alpha$ is an empirical coefficient; $\Delta$ is the slope of the saturation vapor pressure curve at air temperature $\left(\mathrm{hPa} /{ }^{\circ} \mathrm{C}\right) ; \gamma$ is the 
psychrometric constant $\left(\mathrm{hPa} /{ }^{\circ} \mathrm{C}\right) ; R_{n}$ is the net radiation near the surface $(\mathrm{mm} /$ day $) ; G$ is the soil heat flux; $f\left(u_{z}\right)$ is the

183 wind function, which is calculated by Penman's wind function (Penman, 1948), that is, $f\left(u_{2}\right)=0.26\left(1+0.54 u_{2}\right)$, where

$184 u_{2}$ is the wind speeds at $2 \mathrm{~m}$ heights $(\mathrm{m} / \mathrm{s}) ; e_{s}$ is the vapor pressure of the air $(\mathrm{hPa})$; and $e_{a}$ is the saturation vapor

185 pressure at air temperature (hPa). All these variables are calculated by the method recommended by the Food and

186 Agriculture Organization (FAO) of the United Nations (Allen 2000).

\subsubsection{B2015 method}

Brutsaert (2015) generalized the CR to a fourth-order polynomial function between $E T_{a} / E_{P e n}$ and $E T_{w} / E_{P e n}$, the application of which still requires specifying the methods of $E_{P e n}$ and $E T_{w}$. Considering the relationship with nonlinear AA approach, this new polynomial function is regarded as the generalized nonlinear advection-aridity method (B2015) and has the same variables as the nonlinear AA function (Crago et al. 2016; Ma et al. 2019), that is:

$$
\frac{E T_{a}^{B 2015}}{E_{P e n}}=(2-c) \alpha^{2}\left(\frac{E_{r a d}}{E_{P e n}}\right)^{2}-(1-2 c) \alpha^{3}\left(\frac{E_{r a d}}{E_{P e n}}\right)^{3}-c \alpha^{4}\left(\frac{E_{r a d}}{E_{P e n}}\right)^{4}
$$

where $c$ is thought to be zero under usual situations (Brutsaert, 2015). Thus, a fixed $c=0$ and calibrated parameter $\alpha$ of the B2015 have been adopted for daily (Aietal.,2017; Brutsaert et al., 2017; Hu et al., 2018; Zhang et al., 2017), annual, and multi-year scales (Liu et al., 2016). The equation (8) could be represented as:

$$
\frac{E T_{a}^{B 2015}}{E_{P e n}}=2 \alpha^{2}\left(\frac{E_{r a d}}{E_{P e n}}\right)^{2}-\alpha^{3}\left(\frac{E_{r a d}}{E_{P e n}}\right)^{3}
$$

\subsubsection{H2018 method}

196 Han et al. (2018) developed a nonlinear CR method (Han et al. 2012) by introducing minimum ( $x_{\min }$ ) and maximum $197\left(x_{\max }\right)$ limits to $E_{r a d} / E_{P e n}$ (Han and Tian 2018). This sigmoid generalized complementary function (H2018) can be 198 written as:

$$
\frac{E T_{a}^{H 2018}}{E_{\text {Pen }}}=\frac{1}{1+m\left(\frac{x_{\max }-x}{x-x_{\min }}\right)^{n}}
$$

where $x_{\min }$ and $x_{\max }$ corresponding to the minimum and maximum values of $E_{r a d} / E_{P e n} ; x$ is defined as the ratio of $E_{\text {rad }}$ to $E_{P e n}$; and $\mathrm{m}$ and $\mathrm{n}$ are constants. The $\mathrm{H} 2018$ exhibits a three-stage pattern, and $E T_{a} / E_{P e n}$ increases 

parameters $m$ and $n$ can be transferred from $\alpha$ and $b^{-1}$ :

$$
\left\{\begin{array}{c}
n=\frac{4 \alpha\left(1+b^{-1}\right)\left(x_{0.5}-x_{\min }\right)\left(x_{\max }-x_{0.5}\right)}{\left(x_{\max }-x_{\min }\right)} \\
m=\left(\frac{x_{0.5}-x_{\min }}{x_{\max }-x_{0.5}}\right)^{n}
\end{array}\right.
$$

204 where $x_{0.5}=\left(0.5+b^{-1}\right) /\left(\alpha\left(1+b^{-1}\right)\right)$ is the value of $E_{r a d} / E_{P e n}$ corresponding to $E T_{a} / E_{P e n}=0.5$. The linear nonlinear

205 AA function can be regarded as a special case of the H2018 (Han and Tian 2018), for which $x_{\min }=0$ and $x_{\max }=1$ have 206 been suggested for a daily scale because the function and simulated results are not sensitive to $x_{\min }$ and $x_{\max }$.

\subsection{Evaluation criteria}

The performance of the nonlinear AA, B2015 and H2018 methods in simulating monthly $\mathrm{ET}_{\mathrm{a}}$ in the NRB and LCRB was evaluated by water-balance-derived $\mathrm{ET}_{\mathrm{a}}$, in which the optimal model parameters $\alpha$, and $b^{-1}$ are also calibrated. The evaluation criteria included the Nash efficiency coefficient (NSE), the square- $R\left(R^{2}\right)$, the normalized root mean square error (NRMSE), and the relative error between the modeled $\mathrm{ET}_{\mathrm{a}}$ and the observed $\mathrm{ET}_{\mathrm{a}}$.

$$
N S E=1-\frac{\sum_{i=1}^{n}\left(E T_{a}^{m o l, i}-E T_{a}^{o b s, i}\right)^{2}}{\sum_{i=1}^{n}\left(E T_{a}^{o b s, i}-\overline{E T_{a}^{o b s, l}}\right)^{2}}
$$

$$
N R M S E=\frac{\sqrt{\frac{1}{n} \sum_{i=l}^{n}\left(E T_{a}^{m o l, i}-E T_{a}^{o b s, i}\right)^{2}}}{\sqrt{\frac{1}{n-1} \sum_{i=1}^{n}\left(E T_{a}^{m o l, i}-\overline{E T_{a}^{m o l, l}}\right)^{2}}}
$$

213 where $\mathrm{i}$ and $\mathrm{n}$ denote the time series and length of the time sequence, respectively; $E T_{a}^{m o l, i}$ and $E T_{a}^{o b s, i}$ are modeled and 214 observed values, respectively.

\subsection{Contribution of meteorological factors on $\mathbf{E T}_{\mathbf{a}}$}

216 Meteorological factors with strongly physically correlation with $\mathrm{ET}_{\mathrm{a}}$ were selected for analysis, including precipitation, 217 air temperature, relative humidity, wind speed, and sunshine hours ( $\mathrm{Li}$ et al. 2014; Valipour 2015). The contribution rate 
218 of meteorological factors to $\mathrm{ET}_{\mathrm{a}}$ was the sensitivity coefficient of a single meteorological factor multiplied by the multi-

219 year relative change rate of this factor. It could be expressed as follows,

$$
\operatorname{Con}_{V_{i}}=S_{V_{i}} \times R C_{V_{i}}
$$

220 where $V_{i}$ is meteorological factor such as temperature, wind speed, relative humidity, and sunshine hours; $\operatorname{Con}_{V_{i}}$ is the

221 contribution rate of $V_{i}$ to the change in $E T_{a} ; S_{V_{i}}$ is the sensitivity coefficient of $V_{i} ; R C_{V_{i}}(\%)$ is the multi-year relative 222 change rate of $V_{i}$.

223 The dimensionless relative sensitivity coefficient proposed by McCuen (1974) was used to characterize the sensitivity 224 coefficient of $\mathrm{ET}_{\mathrm{a}}$ to climate factors. A simpler and more effective method was to calculate the approximate solution 225 based on the finite difference expansion of Taylor series (Hupet and Vanclooster 2002):

$$
S_{V_{i}}=\frac{\Delta E T}{\Delta V i} \frac{|V i|}{E T}
$$

226 where $E T$ and $\Delta E T$ are the daily $E T_{a}$ and daily variation, respectively; and $V_{i}$ and $\Delta V i$ are the daily meteorological 227 factor values and daily variation, respectively. Under the condition that the variable of a single meteorological factor varies 228 by $\pm 10 \%$, the sensitivity coefficient of $\mathrm{ET}_{\mathrm{a}}$ to each meteorological factor was calculated in turn.

229 The multi-year relative change rate of meteorological factor was calculated by the following formula,

$$
R C_{V_{i}}(\%)=\frac{n \operatorname{Trend}_{V_{i}}}{\left|a V_{i}\right|} \times 100
$$

230 where $a V_{i}$ is the multi-year average value of $V_{i}$; $\operatorname{Trend}_{V_{i}}$ is the annual climate tendency rate of $V_{i}$.

\section{3. Results}

\section{$232 \quad 3.1$ The performance of three developed CR methods in simulating monthly ET $_{\mathbf{a}}$}

233 In this study, the ranges of parameters $\alpha$ of the B2015 was [0.91, 1.13] with an average value of 1.03; the ranges of 234 parameter $\alpha$ and $b^{-1}$ for the nonlinear AA method were $[0.89,1.14]$ and $[0.60,1.51]$, respectively. For the H2018, the 235 range of parameter $\alpha$ was [1.01,1.14] with an average value of 1.05 , and the ranges of parameter $b^{-1}$ was [1.05, 1.78].

236 The performance of the nonlinear AA, B2015, and H2018 methods in simulating monthly ET $_{\mathrm{a}}$ in the NRB and LCRB 237 were compared (Table 1). The discrepancies among the three developed methods for $\mathrm{ET}_{\mathrm{a}}$ estimation was small. The 
238 relative errors between the monthly $\mathrm{ET}_{\mathrm{a}}$ simulated by the nonlinear AA, B2015, and $\mathrm{H} 2018$ methods and the water239 balance-derived $\mathrm{ET}_{\mathrm{a}}$ were $3.5 \%, 4.3 \%$, and 3.5\%, respectively. The NSE of three developed methods were $0.89,0.83$, 240 and 0.91 , respectively. The R-square were 0.90, 0.84, and 0.93 , respectively. And the NRMSE were $0.35 \mathrm{~mm}, 0.37 \mathrm{~mm}$, 241 and $0.28 \mathrm{~mm}$, respectively. Overall, the H2018 performed better than the B2015 and nonlinear AA methods.

242 The performance of three developed CR methods in simulating wet season $\mathrm{ET}_{\mathrm{a}}$ was generally similar with that of annual $243 \mathrm{ET}_{\mathrm{a}}$. It showed a relatively poor performance in simulating dry season $\mathrm{ET}_{\mathrm{a}}$, with the NSE lower than 0.6 except for 244 nonlinear AA method in LCRB. However, the relative errors were less than 10\%, indicating that the methods were able 245 to accurately simulate the average value.

246 In general, the developed CR methods were able to simulate $\mathrm{ET}_{\mathrm{a}}$ with a high accuracy at the annual and wet season scales 247 in the LCRB and NRB. The simulation accuracy of the LCRB was slightly higher than that of the NRB in terms of 248 evaluation criteria.

249 Table 1. Evaluation results of three developed CR methods in simulating monthly ET $_{\mathrm{a}}$.

\begin{tabular}{|c|c|c|c|c|c|c|c|c|c|c|c|c|c|}
\hline & & \multicolumn{3}{|c|}{ NSE } & \multicolumn{3}{|c|}{$\mathrm{R}^{2}$} & \multicolumn{3}{|c|}{ NRMSE $(\mathrm{mm})$} & \multicolumn{3}{|c|}{ Relative error $(\%)$} \\
\hline & & Annual & Dry & Wet & Annual & Dry & Wet & Annual & Dry & Wet & Annual & Dry & Wet \\
\hline non- & NRB & 0.90 & 0.60 & 0.83 & 0.90 & 0.72 & 0.87 & 0.39 & 0.32 & 0.25 & 3.7 & 3.3 & 4.0 \\
\hline AA & LCRB & 0.88 & 0.54 & 0.87 & 0.90 & 0.67 & 0.89 & 0.32 & 0.35 & 0.15 & 3.2 & 3.5 & 3.1 \\
\hline \multirow{2}{*}{ B2015 } & NRB & 0.82 & 0.53 & 0.78 & 0.82 & 0.60 & 0.85 & 0.40 & 0.57 & 0.35 & 5.1 & 5.2 & 4.8 \\
\hline & LCRB & 0.85 & 0.52 & 0.84 & 0.86 & 0.64 & 0.86 & 0.34 & 0.55 & 0.28 & 3.4 & 3.4 & 3.5 \\
\hline \multirow{2}{*}{ H2018 } & NRB & 0.90 & 0.56 & 0.89 & 0.91 & 0.67 & 0.90 & 0.29 & 0.52 & 0.20 & 3.8 & 4.0 & 3.6 \\
\hline & LCRB & 0.92 & 0.57 & 0.91 & 0.94 & 0.70 & 0.93 & 0.28 & 0.52 & 0.15 & 3.2 & 3.6 & 2.8 \\
\hline
\end{tabular}

250 Frequency distributions of the relative error for the nonlinear AA, B2015 and H2018 methods in simulating annual, wet

251 and dry seasons ET $_{\mathrm{a}}$ were shown in Fig.2. In general, the frequency of the relative error of developed CR methods

252 exhibited a normal distribution. In term of the frequency distribution of the H2018 method, more than 95.2\% of the errors

253 were between $-25 \%$ and $25 \%$. Among them, the error frequency between $-5 \%$ and $5 \%$ was the highest, with the value of

$25430.1 \%$. The frequency distribution of wet season was consistent with that of annual series. An $85.7 \%$ margin of error was

255 between $-25 \%$ and $25 \%$. The error frequency was the highest between $-5 \%$ and $5 \%$, with the value of $30.6 \%$.

256 The frequency distribution of the relative error of dry season $\mathrm{ET}_{\mathrm{a}}$ was not consistent with that of wet season. More than $25752.4 \%$ of errors were between $-15 \%$ and $20 \%$. Among them, the highest between $5 \%$ and $10 \%$ with the value of $9.5 \%$. 
The error frequency of $19.4 \%$ was greater than $50 \%$, which was much higher than that of $2.4 \%$ in annual and rainy seasons.

The relative error was slightly higher in dry season in terms of frequency distribution.

The frequency distribution of the relative error for nonlinear AA and B2015 were basically the same as those of H2018.

For example, more than $90 \%$ of the errors were between $-25 \%$ and $25 \%$, and the error frequency was the highest between

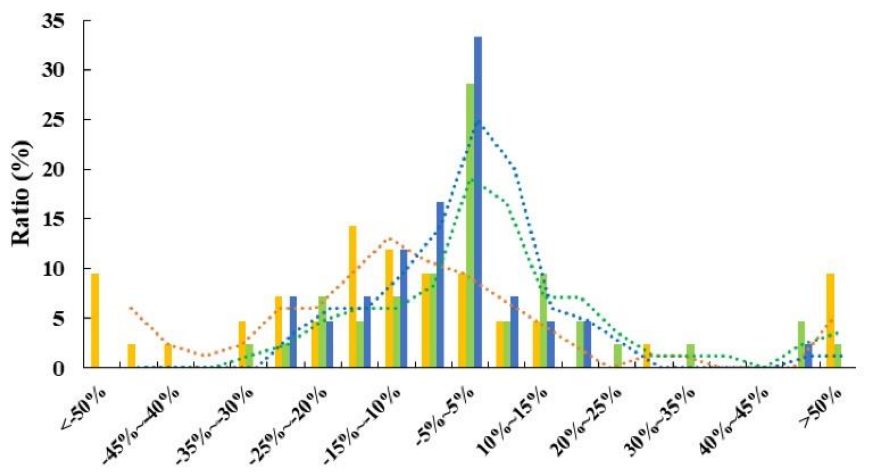

AA error (\%)

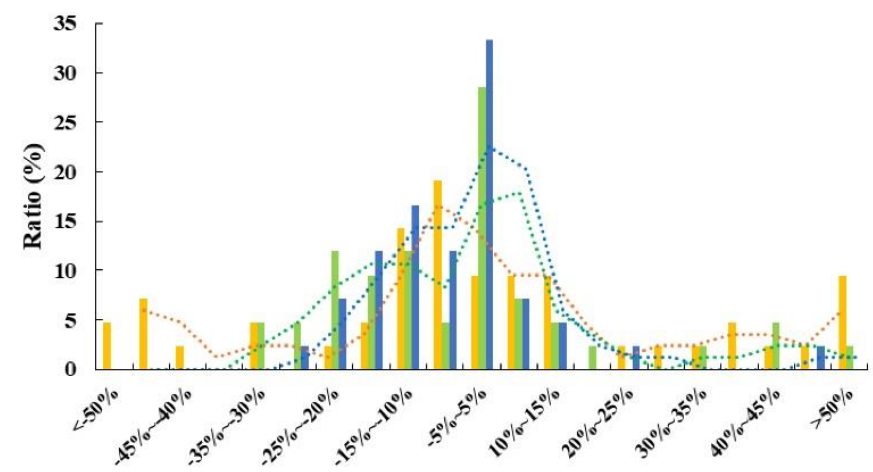

B2015 error (\%)

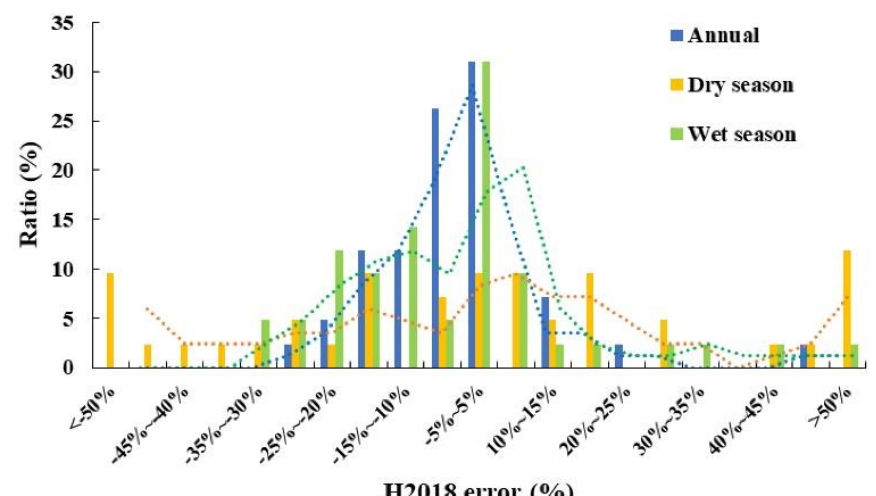

H2018 error (\%)

Fig.2 Frequency distributions of the relative error for the nonlinear AA, B2015 and H2018 methods.

\subsection{Trends of $\mathrm{ET}_{\mathrm{a}}$, precipitation, and runoff in the NRB and LCRB}

Table 2 showed the trends of precipitation, runoff and $\mathrm{ET}_{\mathrm{a}}$ in the NRB and LCRB. In terms of precipitation, the increasing magnitude of the annual precipitation in the NRB and LCRB was $30.5 \mathrm{~mm} / 10 \mathrm{a}$ and $42.0 \mathrm{~mm} / 10 \mathrm{a}$, respectively. The wet season precipitation increased significantly in the LC-M, with the magnitude of $68.4 \mathrm{~mm} / 10 \mathrm{a}$. The magnitude of 
271 increasing trend of dry season precipitation was lower. The contribution rate of increasing magnitude of precipitation in 272 dry season to annual was $24.5 \%$ and $28.0 \%$, respectively. In terms of annual and wet season precipitation series, the mid273 stream region of the two basins showed the highest increasing magnitude, while the upstream region was lowest. The 274 magnitude of increasing trend was $32.4 \mathrm{~mm} / 10 \mathrm{a}$ and $68.4 \mathrm{~mm} / 10 \mathrm{a}$, respectively. The increasing trends of annual and wet 275 season precipitation in the LCRB were significant. The significance level was even exceeded 0.01 .

276 It showed an increasing trend for $\mathrm{ET}_{\mathrm{a}}$ in the upstream region of the LCRB at three temporal scales (dry and wet seasons 277 and annual series). The significant (significance level of 0.05 , the same below) increasing trend was detected for wet 278 season and annual series. The magnitude of increasing trend of three temporal scales was $5.9 \mathrm{~mm} / 10 \mathrm{a}, 14.3 \mathrm{~mm} / 10 \mathrm{a}$, and $27916.3 \mathrm{~mm} / 10 \mathrm{a}$, respectively. The highest increasing magnitude was wet season $\mathrm{ET}_{\mathrm{a}}$ in the LC-D, with the value of $28018.6 \mathrm{~mm} / 10 \mathrm{a}$. On the whole, the annual and wet season $\mathrm{ET}_{\mathrm{a}}$ in each region of the two basins showed an increasing trend. 281 The average magnitude of increasing trend was $13.5 \mathrm{~mm} / 10 \mathrm{a}$ and $15.1 \mathrm{~mm} / 10 \mathrm{a}$, respectively. The increasing magnitude 282 of $\mathrm{ET}_{\mathrm{a}}$ in NRB was downstream region > upstream region > mid-stream region, with the value of $15.2 \mathrm{~mm} / 10 \mathrm{a}, 9.9$ $283 \mathrm{~mm} / 10 \mathrm{a}$, and $9.8 \mathrm{~mm} / 10 \mathrm{a}$, respectively. There was little difference between the upstream, mid-stream and downstream 284 regions of LCRB. The increasing magnitude of annual $\mathrm{ET}_{\mathrm{a}}$ in LCRB was $39.4 \%$ higher than that in NRB. In addition, 285 the dry season $\mathrm{ET}_{\mathrm{a}}$ in the N-U and N-M both exhibited decreasing trends, with the value of $-3.1 \mathrm{~mm} / 10 \mathrm{a}$ and $-1.5 \mathrm{~mm} / 10 \mathrm{a}$, 286 respectively. The variation difference between dry season $\mathrm{ET}_{\mathrm{a}}$ and wet season $\mathrm{ET}_{\mathrm{a}}$ was the most significant in N-M. 287 The increasing magnitude of wet season $\mathrm{ET}_{\mathrm{a}}$ was 7.1 times that of dry season. This is because dry season $\mathrm{ET}_{\mathrm{a}}$ accounted 288 for only $13 \%$ of the annual $\mathrm{ET}_{\mathrm{a}}$. Dry season $\mathrm{ET}_{\mathrm{a}}$ accounted for the highest proportion of annual increasing magnitude in 289 LC-D, with the value of 52.3\%. In addition, precipitation was the main factor that caused $\mathrm{ET}_{\mathrm{a}}$ change. The increasing 290 magnitude of $\mathrm{ET}_{\mathrm{a}}$ accounted for $44.8 \%$ of the precipitation increment.

291 Runoff in the NRB showed increasing trends at three temporal scales. The increasing magnitude of annual series for the 292 whole basin was $29.3 \mathrm{~mm} / 10 \mathrm{a}$. The highest and the lowest increasing magnitude of annual series were in the mid-stream 293 and upstream regions, with the value of $38.0 \mathrm{~mm} / 10 \mathrm{a}$ and $23.5 \mathrm{~mm} / 10 \mathrm{a}$, respectively. This was consistent with the 294 magnitude of precipitation, indicating the changes of runoff were mainly caused by that of precipitation in the NRB. The 295 highest increasing magnitude of wet season series was $35.4 \mathrm{~mm} / 10 \mathrm{a}$ in the mid-stream region, which was consistent with 296 that of annual series. The significant increasing trends of dry season runoff in the NRB and wet season runoff in the N-D 
297 were detected. The significance level was even exceeded 0.01. In addition, the difference between the increasing 298 magnitude of precipitation and runoff in the $\mathrm{N}-\mathrm{U}$ was lower than that of $\mathrm{ET}_{\mathrm{a}}$. This indicated that there was glacial melt 299 water in this region to replenish the $\mathrm{ET}_{\mathrm{a}}$.

300 Runoff in the LCRB except for the LC-U also exhibited increasing trends at three temporal scales, with the magnitude of 301 annual series for the whole basin was $15.8 \mathrm{~mm} / 10 \mathrm{a}$. The significant increasing trends of dry and wet reasons, and annual 302 runoff were also detected in the mid-stream region. The magnitude was $13.4 \mathrm{~mm} / 10 \mathrm{a}, 49.8 \mathrm{~mm} / 10 \mathrm{a}$, and $56.5 \mathrm{~mm} / 10 \mathrm{a}$, 303 respectively. The decreasing trends of runoff were detected in the LC-U. The annual magnitude was $-13.8 \mathrm{~mm} / 10 \mathrm{a}$. In 304 other words, according to the hydrological budget balance, the increasing precipitation cannot meet the increasing water 305 consumption by $\mathrm{ET}_{\mathrm{a}}$. This might be the reason for the decreasing runoff.

Table 2. Trends of precipitation, $\mathrm{ET}_{\mathrm{a}}$ and runoff in the NRB and LCRB during 1956-2018.

\begin{tabular}{|c|c|c|c|c|c|c|c|c|c|}
\hline \multirow{2}{*}{\multicolumn{2}{|c|}{ Slope $(\mathrm{mm} / 10 \mathrm{a})$}} & \multicolumn{3}{|c|}{ NRB } & \multirow[b]{2}{*}{ NRB } & \multicolumn{3}{|c|}{ LCRB } & \multirow[b]{2}{*}{ LCRB } \\
\hline & & $\mathrm{N}-\mathrm{U}$ & N-M & N-D & & LC-U & LC-M & LC-D & \\
\hline \multirow{3}{*}{$\begin{array}{l}\text { Precipitation } \\
\qquad \text { (P) }\end{array}$} & Dry season & 3.3 & 4.9 & 15.8 & 7.5 & 5.5 & 8.2 & 20.9 & 11.8 \\
\hline & Wet season & 16.3 & 31.8 & 37.3 & 28.3 & 16 & $65.8 * *$ & 30.5 & 34.3 \\
\hline & Annual & 19.4 & 32.4 & 40.9 & 30.5 & 25.7 & $68.4 * *$ & 40 & 42 \\
\hline \multirow{3}{*}{$\mathrm{ET}_{\mathrm{a}}$} & Dry season & -3.1 & -1.5 & 6 & 0.1 & 5.9 & 5.6 & 7.7 & 6.5 \\
\hline & Wet season & 10.2 & 10.6 & 13.1 & 11.2 & $14.3^{* *}$ & 13.9 & 18.6 & 15.7 \\
\hline & Annual & 9.9 & 9.8 & 15.2 & 11.4 & $16.3^{* *}$ & 18.8 & 21.3 & 18.8 \\
\hline \multirow{3}{*}{ Runoff (R) } & Dry season & $8.7 * *$ & $8.2^{* *}$ & $3.4^{* *}$ & 7 & -1.1 & $13.4^{* *}$ & 2.7 & 4.1 \\
\hline & Wet season & 19.4 & 35.4 & $19.9 * *$ & 25.7 & -13.4 & $49.8 * *$ & 16 & 13.7 \\
\hline & Annual & 23.5 & 38 & 24.1 & 29.3 & -13.8 & $56.5 * *$ & 17.2 & 15.8 \\
\hline
\end{tabular}

$307 *$ and $* *$ represent the significance level of 0.05 and 0.01 respectively.

308 Since H2018 had a best simulation effect, the simulation results of ET $_{a}$ distribution in the NRB and LCRB from 1958 to

3092018 were selected to replace the years in which the data of hydrological budget balance method were missing (Fig.3).

310 Annual precipitation increased from northwest to southeast. The precipitation of most stations (13/18) in the two basins

311 showed an increasing trend, with an increasing magnitude of $2.4-124.4 \mathrm{~mm} / 10 \mathrm{a}$. The precipitation at three stations

312 increased significantly $(85.2-144.1 \mathrm{~mm} / 10 \mathrm{a})$. While the precipitation at five stations showed a decreasing trend, with the

313 value of $-50.6--17.3 \mathrm{~mm} / 10 \mathrm{a}$. Most of stations showed an increasing trend in the dry season. Only five stations showed a

314 decreasing trend, and mainly located in the mid-stream region (3/5). The decreasing magnitude of them between -56.3- -

$3150.6 \mathrm{~mm} / 10 \mathrm{a}$. The trend of dry season precipitation in the mid-stream region was opposite to that of the whole basin, which 
316 was consistent with the above results (Table 2). The trend of wet season precipitation was basically consistent with that

317 of annual precipitation. And more stations showed an increasing trend (15/18).

318 The spatial distribution of $\mathrm{ET}_{\mathrm{a}}$ was highly consistent with precipitation. The $\mathrm{ET}_{\mathrm{a}}$ in NRB and LCRB were downstream

319 region > upstream region > mid-stream region. In the LCRB, for example, the annual $\mathrm{ET}_{\mathrm{a}}$ in the downstream region

$320(650.4 \mathrm{~mm})$ was three times that in the upstream region $(217.6 \mathrm{~mm})$. In addition, $\mathrm{ET}_{\mathrm{a}}$ at most stations $(16 / 18)$ showed an

321 increasing trend in recent 60 years. The increasing magnitude of NRB and LCRB was $17.0 \mathrm{~mm} / 10 \mathrm{a}$ and $27.1 \mathrm{~mm} / 10 \mathrm{a}$,

322 respectively. A few downstream stations (2/18) had a decreasing tread, with the decreasing magnitude between -4.8 and -

$3231.9 \mathrm{~mm} / 10 \mathrm{a} . \mathrm{ET}_{\mathrm{a}}$ decreased more in dry season than in annual (4/18). From the trend of annual increasing $\mathrm{ET}_{\mathrm{a}}$, the

324 decreasing magnitude in dry season was less than the increasing magnitude in wet season.
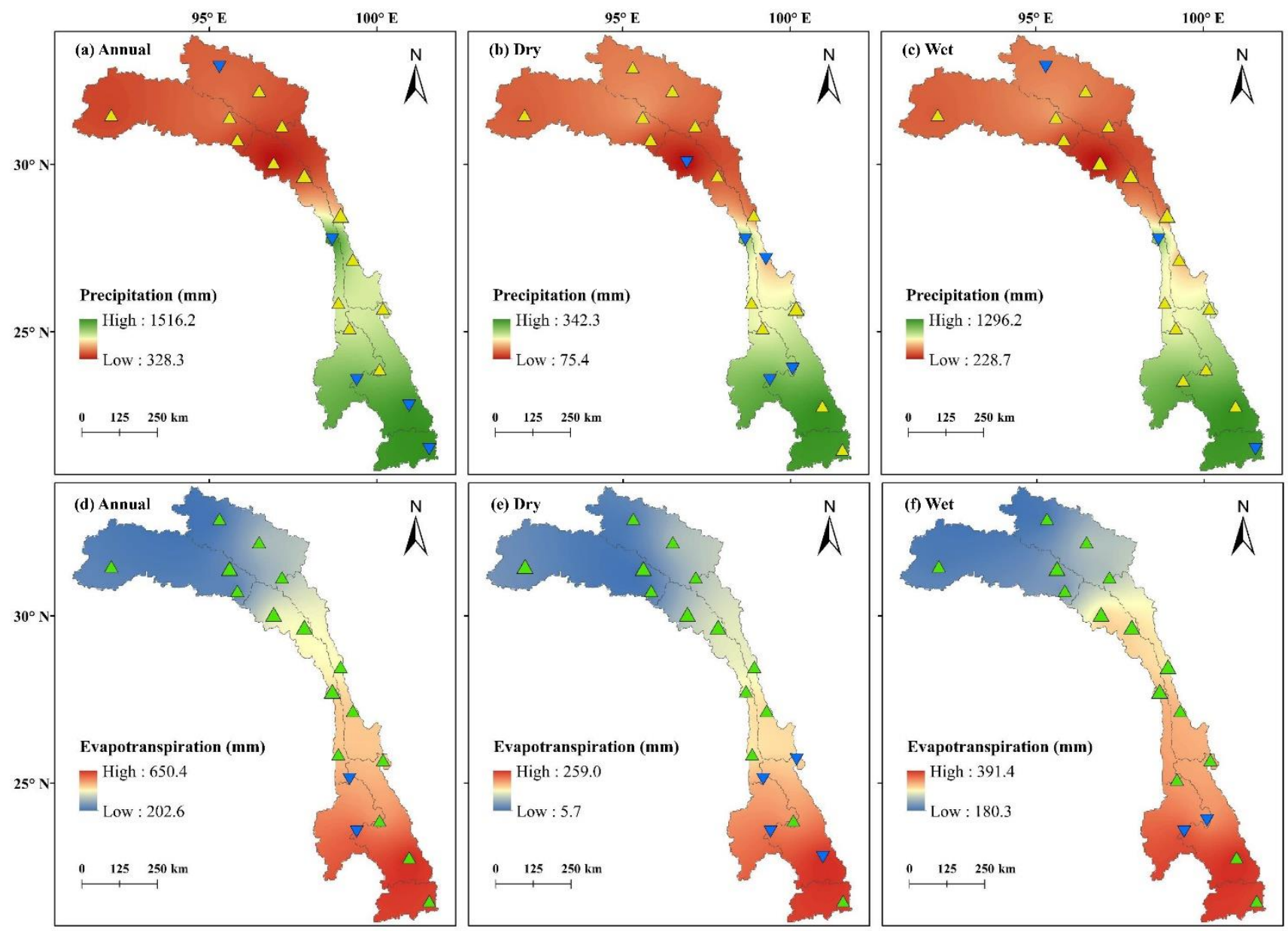

325 
Fig.3 Annual and seasonal trends of precipitation and $\mathrm{ET}_{\mathrm{a}}$ at each station from 1956 to 2018 simulated by $\mathrm{H} 2018$ method (Yellow/Green triangles represent increase trends, and blue triangles are decreasing trends. Large symbols indicate the significance level of 0.05).

\subsection{Contribution of meteorological factors on $\mathrm{ET}_{\mathrm{a}}$}

330 Precipitation, temperature and humidity increased from south to north in NRB and LCRB (Fig.4), which was consistent 331 with the spatial distribution of $\mathrm{ET}_{\mathrm{a}}$. On the contrary, wind speed decreased in this direction. The sunshine hours were the 332 shortest in the mid-stream region, which was especially significant in wet season. In other words, latitude and topography 333 affected the regional climate, and the geographical characteristics of different meteorological factors were bound to have 334 different influences on $\mathrm{ET}_{\mathrm{a}}$.

335 Air temperature in the basins exhibited significant increasing trends at all temporal scales (dry and wet seasons and annual 336 series) during the past 60 years. On the contrary, wind speed showed significant decreasing trends. There was little 337 difference for trends of air temperature between annual and dry season series at observed stations. It only showed a 338 decreasing trend at one station located at the mid-stream region of the NRB. But decreasing trends were detected at four 339 stations, which were located in the upstream region of the LCRB and the mid-stream of two basins, for air temperature of 340 wet seasons. The variation characteristics of relative humidity also showed a high consistency among three temporal scales 341 at observed stations. But it showed regional variations. The increasing humidity was detected at the upstream and mid342 stream regions. While most downstream sites showed a decreasing trend. The number of decreasing humidity in the dry 343 season (7/18) was more than that in the wet season (4/18).

344 Sunshine hours in the LCRB exhibited significant decreasing trends at all temporal scales (7/9). It only showed an 345 increasing trend at two stations located at the boundary of the downstream region. However, there was a seasonal and 346 regional differences in the NRB. The decreasing sunshine hours were detected at the upstream and mid-stream regions. 347 While downstream sites increased slightly. Compared with the dry season sunshine hours, the wet season hours showed 348 an increasing trend with four more observed stations in the upstream and mid-stream regions. The spatial and temporal 349 distribution and variation trend of different meteorological factors would have different effects on regional $\mathrm{ET}_{\mathrm{a}}$. 

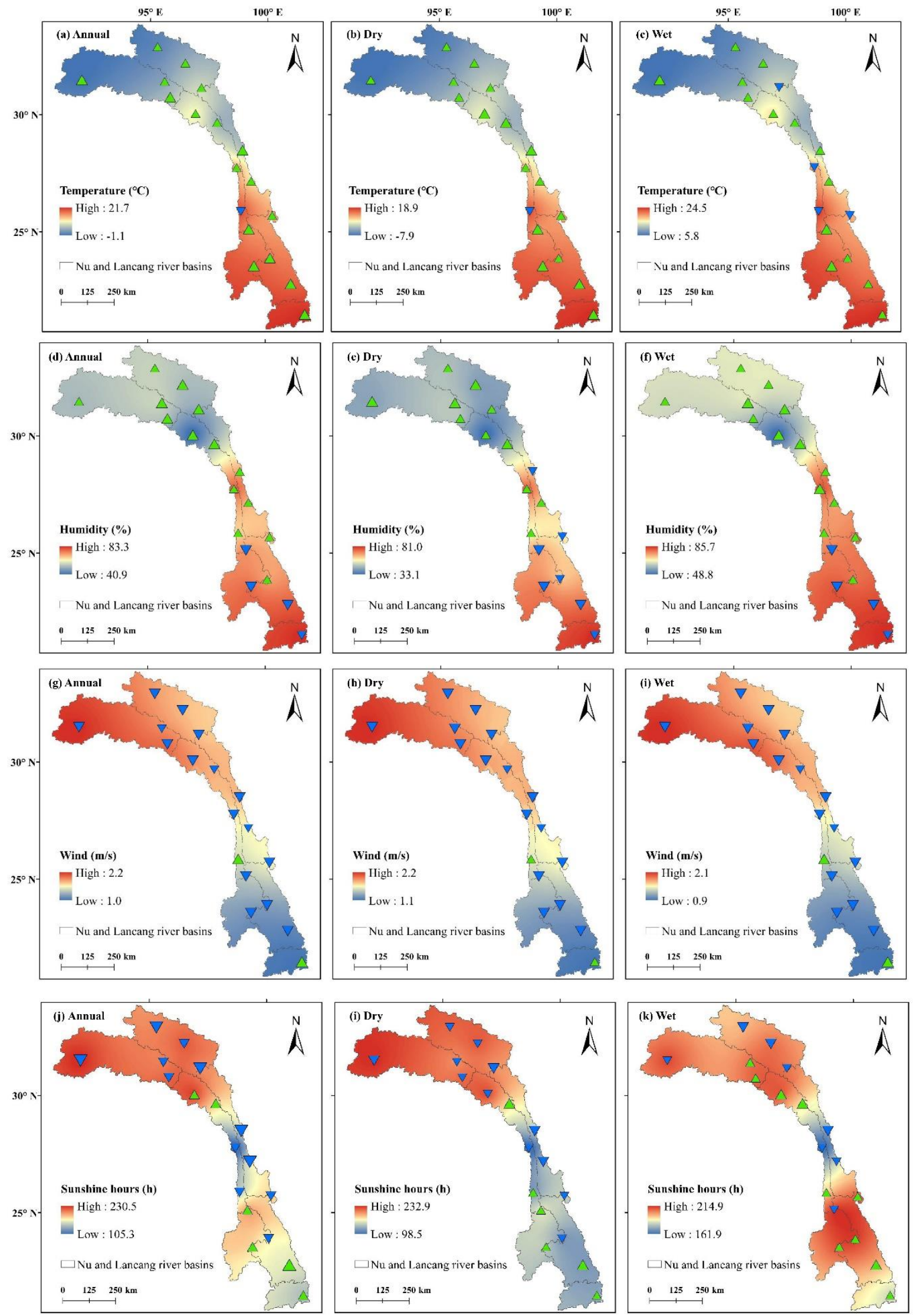
351 Fig.4 Annual and seasonal trends of major meteorological variables in the NRB and LCRB during the past 60 years (Green triangles represent increasing trends, and blue triangles are decreasing trends. Large symbols indicate the significance level of 0.05).

354 The contribution rate of meteorological factors to $\mathrm{ET}_{\mathrm{a}}$ was shown in Fig.5. The contribution rates of increasing air 355 temperature to the increasing $\mathrm{ET}_{\mathrm{a}}$ in the NRB and LCRB were $23.3 \%$ and $23.7 \%$, respectively. Relative humidity, wind 356 speed and sunshine hours all had negative contributions to $\mathrm{ET}_{\mathrm{a}}$. Among them, the contribution rates of increasing humidity 357 were $-12.5 \%$ and $-9.2 \%$, the contribution rates of decreasing wind speed were $-10.8 \%$ and $-9.6 \%$, and the contribution 358 rates of decreasing sunshine hours were $-6.5 \%$ and $-4.1 \%$ in the NRB and LCRB, respectively. The impacts of 359 meteorological factors on $\mathrm{ET}_{\mathrm{a}}$ in the basins were basically consistent in the dry and wet seasons except for the N-U and 360 N-M. Contributions of annual and dry season meteorological factors were mainly different in the regions. The positive 361 contribution of dry season humidity, wind speed, and sunshine to the total was $13.3 \%$ and $13.4 \%$ in the N-U and N-M, 362 respectively. While the wet season total contributions were $-8.8 \%$ and $-25.7 \%$, and annual total contributions were $-24.8 \%$ 363 and $-21.7 \%$, respectively. In addition, the performance of the wet season sunshine hours in the N-D was completely 364 opposite to that in other areas. The increasing wet season sunshine hours contributed $9.0 \%$ to the increasing $\mathrm{ET}_{\mathrm{a}}$ in the 365 N-D. The two basins mainly relied on the positive contribution of air temperature, which was the dominant factor leading 366 to the increase of $\mathrm{ET}_{\mathrm{a}}$. Humidity and wind speed were also very important meteorological impact factors. The changes of 367 meteorological factors in different regions and seasons caused spatiotemporal variation of $\mathrm{ET}_{\mathrm{a}}$, and provided 368 positive/negative contributions to the regional $\mathrm{ET}_{\mathrm{a}}$. 

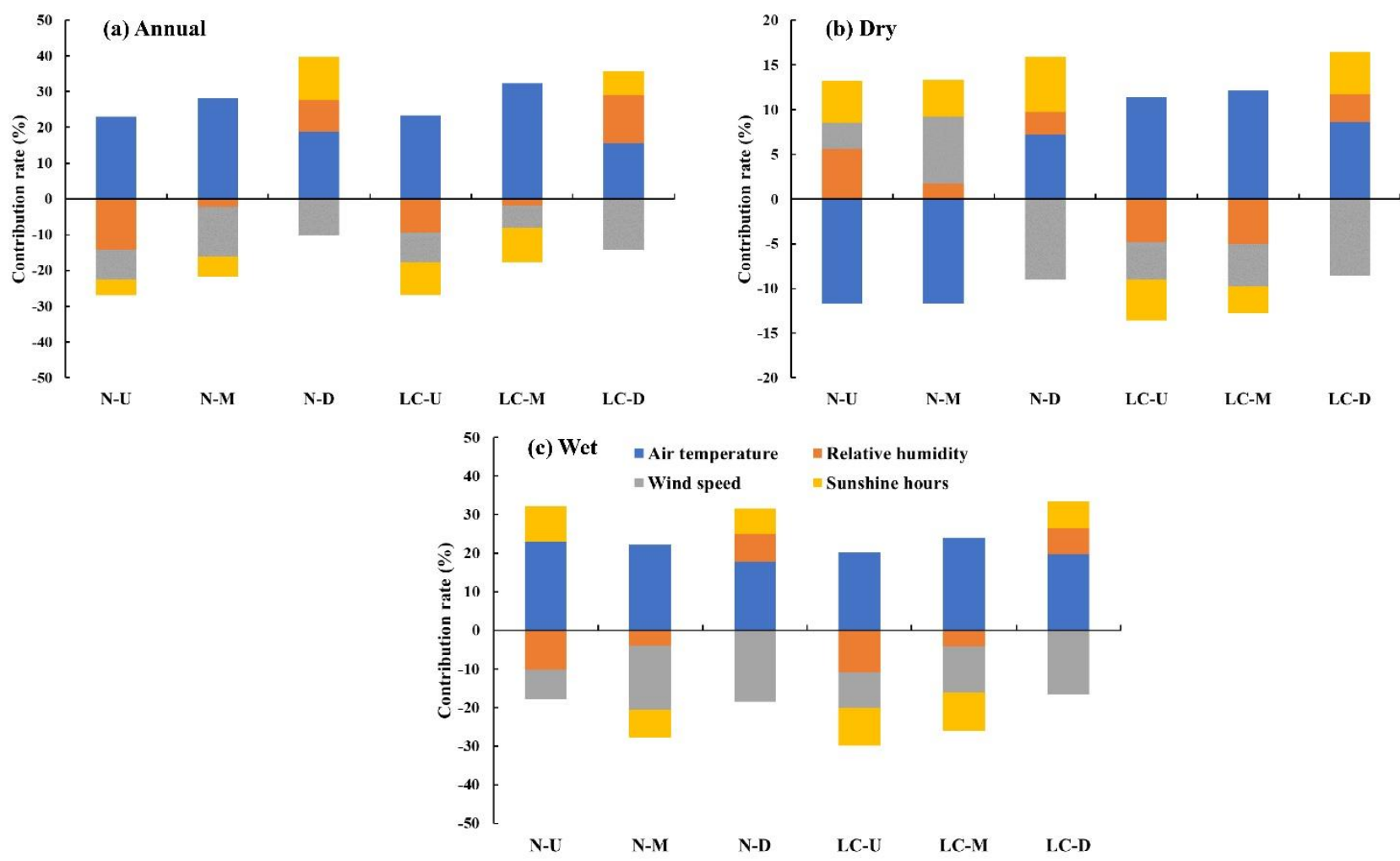

Fig.5 The contribution of meteorological factors on $\mathrm{ET}_{\mathrm{a}}$.

371 The correlation coefficients between meteorological factors and $\mathrm{ET}_{\mathrm{a}}$ in the NRB and LCRB were shown in Fig.6. There

372 was a positive correlation between $\mathrm{ET}_{\mathrm{a}}$ and precipitation, temperature, wind and sunshine hours. The correlation between

$373 \mathrm{ET}_{\mathrm{a}}$ and precipitation in wet season was higher than that in dry season. There was little difference among seasonal

374 correlation coefficients for other meteorological factors. The correlation between $\mathrm{ET}_{\mathrm{a}}$ and precipitation and temperature 375 in the LC-M was the highest, reaching 0.81 and 0.68 , respectively. In mid-stream region of the NRB, $\mathrm{ET}_{\mathrm{a}}$ was with the 376 strongest correlation with wind speed, and the correlation coefficient was higher than 0.80 . The correlation between $\mathrm{ET}_{\mathrm{a}}$ 377 and sunshine hours in the wet season in up-stream region of the LCRB reached 0.73 . There was a negative correlation 378 between $\mathrm{ET}_{\mathrm{a}}$ and relative humidity in the whole basin. The negative correlation was particularly strong in the N-M, LC-

$379 \mathrm{U}$ and LC-M. The correlation coefficients were all greater than -0.65 . 


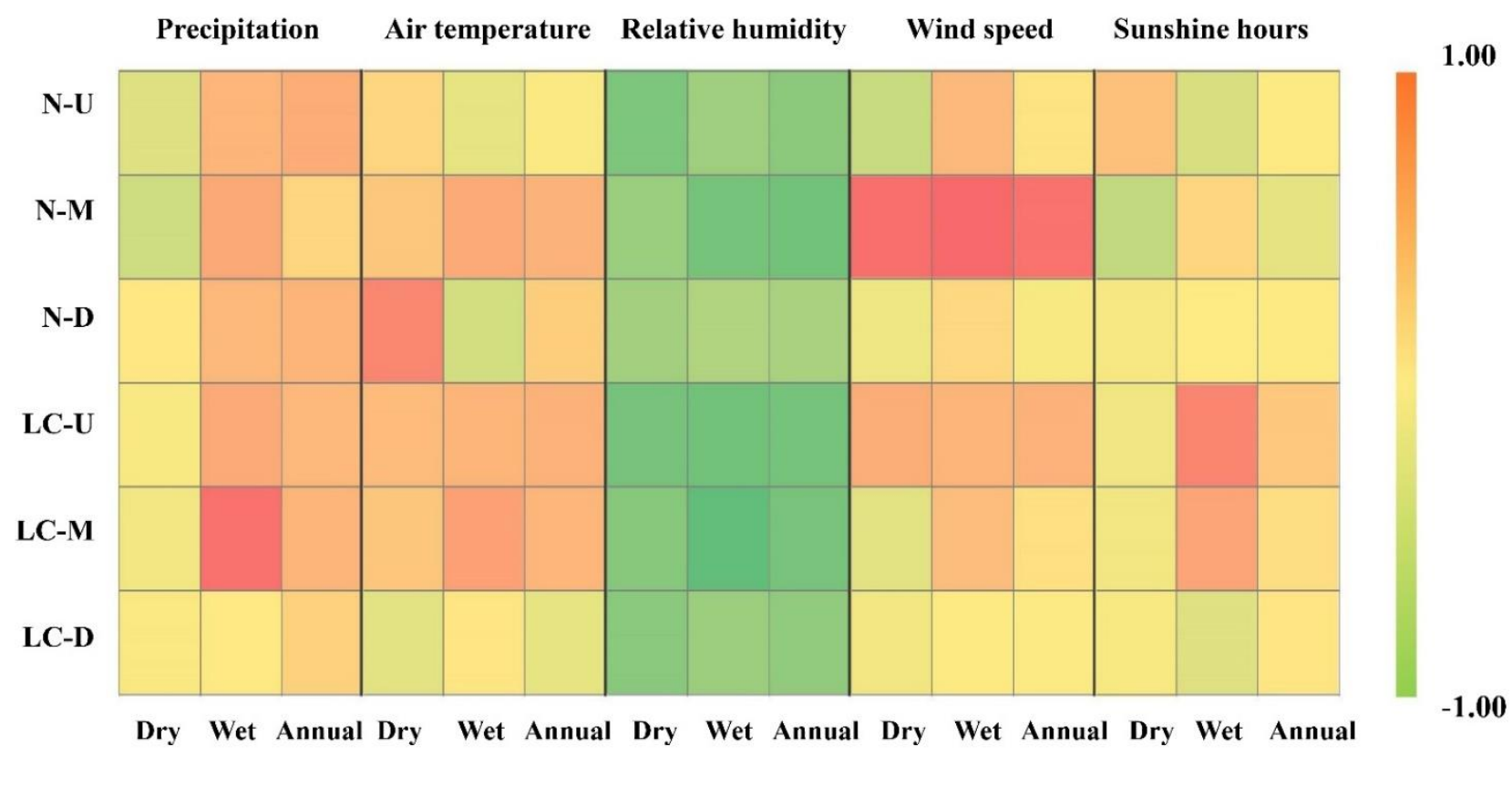

Fig.6 The correlations between meteorological factors and $\mathrm{ET}_{\mathrm{a}}$.

\section{Discussions}

383 The parameter $\alpha$ is related to the natural characteristics. Researches pointed out that the parameter $\alpha$ in the Priestly-

384 Taylor formula had a wider range of value with roughly 0.6-1.5 (DeBruin 1983; McMahon et al. 2013), which represented

385 the combined effects of the land-atmosphere coupling relationship and underlying vegetation, soil and water conditions

386 on the complementary relationship of $\mathrm{ET}_{\mathrm{a}}$. In this study, the value of the parameter $\alpha$ was negatively correlated with the

387 regional aridity index $(\mathrm{AI}=E T / P)$ in the basins (Fig.7), which was consistent with Liu et al. (2016). 


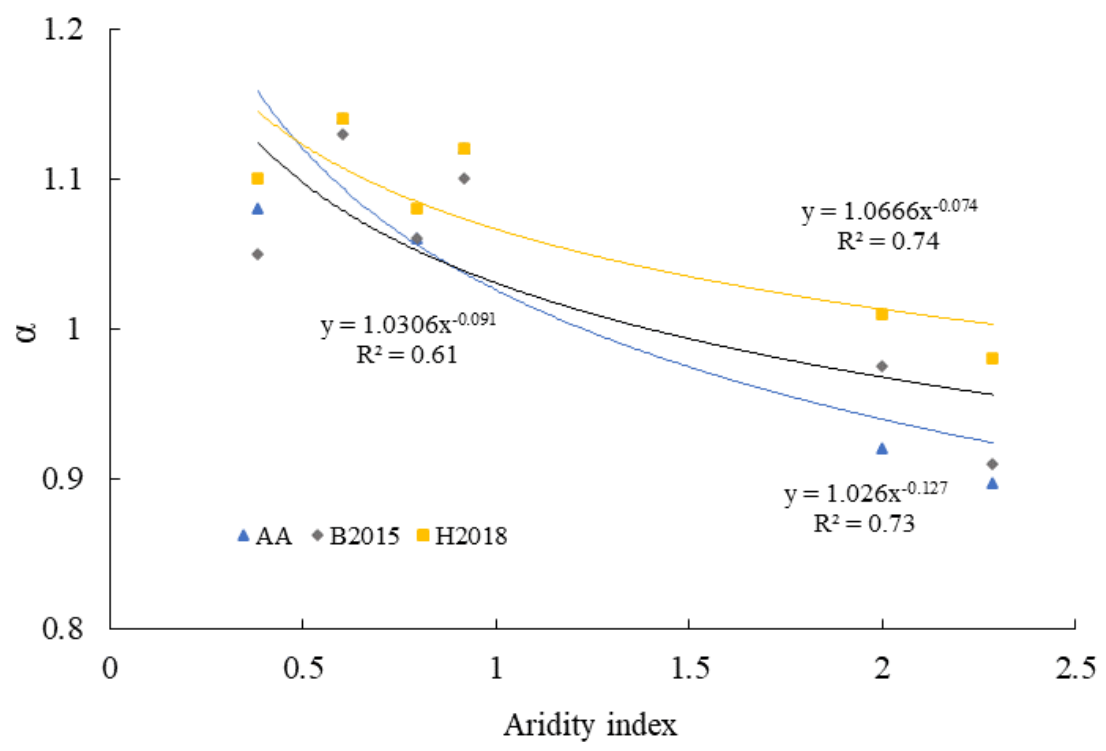

Fig.7 Negative correlation between $\mathrm{AI}$ and $\alpha$ value.

390 Gao et al. (2018) and Zhou et al. (2020) respectively estimated the $\mathrm{ET}_{\mathrm{a}}$ distribution in the upstream region of Huaihe 391 river basin and the Loess Plateau based on the generalized complementary principle (B2015 and H2018). The results 392 showed that the simulation accuracy of H2018 was higher than that of B2015 in the Huaihe River basin and the Loess 393 Plateau, and the results are consistent with that in the LCRB and NRB. Gao et al. (2018) pointed out that when $\alpha=1.25$, 394 the relative error of the method was within $\pm 5 \%$. Zhou et al. (2020) showed that H2018 and B2015 had the best 395 performance when $\alpha=1.05$ and 1.14 , respectively. The $\alpha$ value in the basins studied in this paper was relatively low. It 396 is possible that the LCRB and NRB have higher aridity index which is related to the local climatic conditions and vegetation coverage. The developed CR methods after parameter adjustment has good performance in different regions,

398 which provides more references and possibilities for the study of regional $\mathrm{ET}_{\mathrm{a}}$.

$399 \mathrm{ET}_{\mathrm{a}}$ is directly sourced from soil water, open water, and indirectly from water by vegetation (Balugani et al. 2016). 400 Precipitation affects $\mathrm{ET}_{\mathrm{a}}$ through soil moisture constraints, especially in arid regions. For example, with high 401 precipitation, $\mathrm{ET}_{\mathrm{a}}$ is less limited to soil moisture, and the $\mathrm{ET}_{\mathrm{a}}$ might be the same as the potential evapotranspiration (Liu 402 et al. 2012). However, in arid environments with limited precipitation, the soil water content is insufficient, and $\mathrm{ET}_{\mathrm{a}}$ tends 403 to be largely dependent on available soil water. The arid environment places a strong constraint on $\mathrm{ET}_{\mathrm{a}}$, causing the $\mathrm{ET}_{\mathrm{a}}$ 404 to be much lower than potential evapotranspiration. High temperature accelerates $\mathrm{ET}_{\mathrm{a}}$ by providing more energy. And 405 the longer sunshine hours mean that more solar radiation energy is provided. Therefore, $\mathrm{ET}_{\mathrm{a}}$ is sensitive to both 
temperature and sunshine ( $\mathrm{Li}$ et al. 2017). Wind speed, another meteorological factor positively related to $\mathrm{ET}_{\mathrm{a}}$, is responsible for transporting water heat and carbon dioxide. Wind is in some cases dominating radiation (Liu and Zhang 2013). There is a negative correlation between the relative humidity and $\mathrm{ET}_{\mathrm{a}}$. With an increase in humidity, the moisture content in the air is higher and moisture evaporated into the air decreases (Moratiel et al. 2010). As demonstrated in this

410 study meteorological factors had different effects on $\mathrm{ET}_{\mathrm{a}}$ at different time scales in different regions. The quantitative 411 relationship between regional $\mathrm{ET}_{\mathrm{a}}$ and climate and soil-plant-atmosphere continuum should be considered in the future.

\section{5. Conclusions}

413 Monthly $\mathrm{ET}_{\mathrm{a}}$ in the LCRB and NRB were simulated by the hydrological budget balance method based on the observed

414 hydrological and meteorological data from 1956 to 2018. The nonlinear AA and two generalized complementary functions, 415 B2015 and H2018 were evaluated by monthly water-balance-derived values. Impacts of major meteorological factors on $416 \mathrm{ET}_{\mathrm{a}}$ were also assessed. The conclusions were as follows,

417 (1) All three developed CR methods were able to accurately simulate monthly $\mathrm{ET}_{\mathrm{a}}$ series. The NSE between the 418 monthly $\mathrm{ET}_{\mathrm{a}}$ simulated by the nonlinear AA, B2015, and H2018 methods and the water-balance-derived values 419 were $0.89,0.83$, and 0.91 , respectively. The R-square were $0.90,0.84$, and 0.93 , respectively. The difference between NSE and R-square was highest in dry season $\mathrm{ET}_{\mathrm{a}}$, with an average of 0.55 and 0.67 , respectively. Overall, the $\mathrm{H} 2018$ method showed the relatively best performance. The parameter $\alpha$ had a negative correlation with the regional aridity index.

(2) Annual $\mathrm{ET}_{\mathrm{a}}$ and precipitation showed significant increasing trends during 1956-2018 in the basins at all temporal scales (dry and wet seasons and annual series). Runoff also exhibited an increasing trend in each sub-basin, except for the downstream region of the LCRB. The increasing magnitude was downstream region > mid-stream region > upstream region. The increasing magnitudes of wet reason precipitation and runoff in the mid-stream region was the highest, with the value of $73.7 \mathrm{~mm} / 10 \mathrm{a}$ and $44.9 \mathrm{~mm} / 10 \mathrm{a}$, respectively. The $\mathrm{ET}_{\mathrm{a}}$ increased dramatically in the downstream region, the magnitude reached $25.9 \mathrm{~mm} / 10 \mathrm{a}$. Precipitation was the main factor leading to $\mathrm{ET}_{\mathrm{a}}$ change. The increasing magnitude of $\mathrm{ET}_{\mathrm{a}}$ accounted for $42.4 \%$ of the precipitation increment. 
(3) The contribution rate of air temperature to $\mathrm{ET}_{\mathrm{a}}$ was the highest, reaching $23.5 \%$, which showed a significant positive correlation. The second was wind speed, whose contribution rate was $-10.2 \%$ on average, and even reached $-14.1 \%$ in the upstream region of the NRB. The correlation coefficient between $\mathrm{ET}_{\mathrm{a}}$ and wind speed was highest in mid-stream region of the NRB, which was greater than 0.80 . The contribution rates of increasing humidity to $\mathrm{ET}_{\mathrm{a}}$ were $-12.5 \%$ and $-9.2 \%$ in the NRB and LCRB, respectively. $\mathrm{ET}_{\mathrm{a}}$ was negatively correlated with humidity. The negative correlation was especially strong in the mid-stream region, with coefficients were greater than -0.65 . The (XDA2006020202; XDA23090302) and National Natural Science Foundation of China (41571027).

\section{References}

Allen RG (2000) Using the FAO-56 dual crop coefficient method over an irrigated region as part of an evapotranspiration intercomparison study. J Hydrol 229:27-41. http://doi.org/10.1016/ S0022-1694(99)00194-8

Allen R, Irmak A, Trezza R, Hendrickx JMH, Bastiaanssen W, Kjaersgaard J (2011) Satellite-based ET estimation in agriculture using SEBAL and METRIC. Hydrol Process 25:4011-4027. http://doi.org/10.1002/hyp.8408

Balugani E, Lubczynski MW, Metselaar K (2016) A framework for sourcing of evaporation between saturated and unsaturated zone in bare soil condition. Hydrol Sci J 61:1981-1995. http://doi.org/ 10.1080/02626667.2014.966718

447 Bouchet RJ (1963) Evapotranspiration réelle et potentielle, signification climatique. IAHS Publ 62:134-142

448 Brutsaert W (2015) A generalized complementary principle with physical constraints for land surface evaporation. Water Resour Res 51:8087-8093. http://doi.org/10.1002/2015WR017720

450 Brutsaert W, Parlange MB (1998) Hydrologic cycle explains the evaporation paradox. Nature 396:30. http://doi.org/10.1038/23845 
Brutsaert W, Cheng L, Zhang L (2020) Spatial distribution of global landscape evaporation in the early twenty first century by means of a generalized complementary approach. J Hydrometeorol 21:287-298. http://doi.org/10.1175/JHM-D$19-0208.1$

Brutsaert W, Li W, Takahashi A, Hiyama T, Zhang L, Liu W (2017) Nonlinear advection-aridity method for landscape evaporation and its application during the growing season in the southern Loess Plateau of the Yellow River basin. Water Resour Res 53:270-282. http://doi.org/ 10.1002/2016WR019472

Chen ZJ, Zhu ZC, Jiang H, Sun SJ (2020) Estimating daily reference evapotranspiration based on limited meteorological data using deep learning and classical machine learning methods. J Hydrol 591:125286. http://doi.org/10.1016/j.jhydrol.2020.125286

Crago R, Szilagyi J, Qualls R (2016) Rescaling the complementary relationship for land surface evaporation. Water Resour Res 52:8461-8471. http://doi.org/10.1002/2016WR019753

DeBruin HAR (1983) A model method for the Priestley-Taylor parameter $\alpha$. J Clim Appl Meteorol 22:572-578. https://doi.org/10.1175/1520-0450(1983)022<0572:AMFTPT>2.0.CO;2

Fan H, He DM (2015) Temperature and precipitation variability and its effects on streamflow in the upstream regions of

Fan JL, Yue WJ, Wu LF, Zhang FC, Cai HJ, Wang XK, Lu XH, Xiang YZ (2018) Evaluation of SVM, ELM and four

Farahani HJ, Howell TA, Shuttleworth WJ, Bausch WC (2007) Evapotranspiration: Progress in measurement and modeling in agriculture. Trans ASABE 50:1627-1638

Fisher JB, Melton F, Middleton E, Hain C, Anderson M, Allen R, Wood EF (2017) The future of evapotranspiration: Global requirements for ecosystem functioning, carbon and climate feedbacks, agricultural management, and water resources. Water Resour Res 53:2618-2626. https://doi.org/10.1002/2016WR020175

Gao G, Chen DL, Xu CY, Simelton E (2007) Trend of estimated actual evapotranspiration over China during 1960-2002. J Geophysl Res Atmos 112:D11120. https://doi.org/10.1029/2006JD008010 
Gao JQ, Qiao M, Qiu XF, Zeng Y, Hua HH, Ye XZ, Adamu M (2018) Estimation of actual evapotranspiration distribution in the Huaihe River upstream basin based on the generalized complementary principle. Adv Meteorol 2018:2158168. https://doi.org/10.1155/2018/2158168

Granger RJ, Gray DM (1989) Evaporation from natural nonsaturated surfaces. J Hydrol 111:21-29. https://doi.org/10.1016/0022-1694(89)90249-7

Han SJ, Tian FQ (2018) Derivation of a sigmoid generalized complementary function for evaporation with physical constraints. Water Resour Res 54:5050-5068. https://doi.org/10.1029/2017WR021755

Han SJ, Hu H, Tian FQ (2008) Evaluating the advection-aridity model of evaporation using data from field-sized surfaces of HEIFE. International Symposium on Flood Forecasting and Water Resource Assessment for IAHS-PUB.

Hobbins MT, Ramirez JA, Brown TC, Claessens, LHJM (2001) The complementary relationship in estimation of regional evapotranspiration: The complementary relationship areal evapotranspiration and advection-aridity models. Water Resour Res 37:1367-1387. https://doi.org/10.1029/2000WR900358

Hupet F, Vanclooster M (2002) Effect of the sampling frequency of meteorological variables on the estimation of the reference evapotranspiration. J Hydrol 243:192-204. https://doi.org/10.1016/S0022-1694(00)00413-3

Jian DN, Li XC, Sun HM, Tao H, Jiang T, Su BD, Hartmann H (2020) Estimation of actual evapotranspiration by the complementary theory-based advection-aridity model in the Tarim River basin, China. J Hydrometeorol 19:289-303. https://doi.org/10.1175/JHM-D-16-0189.1

Katul GG, Oren R, Manzoni S, Higgins C, Parlange MB (2012) Evapotranspiration: A process driving mass transport and energy exchange in the soil-plant-atmosphere-climate system. Rev Geophys 50:RG3002. https://doi.org/10.1029/2011RG000366

Li B, Chen F, Liu XM (2017) Sensitivity of the Penman-Monteith reference evapotranspiration to sunshine duration in the upper Mekong River basin. Hydrol Sci J 62:830-842. https://doi.org/ 10.1080/02626667.2016.1243286

Li XP, Wang L, Chen DL, Yang K, Wang AH (2014) Seasonal evapotranspiration changes (1983-2006) of four large basins on the Tibetan Plateau. J Geophys Res 119:13079-13095. https://doi.org/10.1002/2014JD022380 
Liu M, Bardossy A, Li J (2012) Physically-based modeling of topographic effects on spatial evapotranspiration and soil moisture patterns through radiation and wind. Hydrol Earth Syst Sci 16:357-373. https://doi.org/10.5194/hess-16$357-2012$

Liu WB, Wang L, Zhou J, Li YZ, Sun FB, Fu GB, Li XP, Sang YF (2016) A worldwide evaluation of basin-scale

Liu XM, Zhang D (2013) Trend analysis of reference evapotranspiration in Northwest China: The roles of changing wind speed and surface air temperature. Hydrol Process 27:3941-3948. https://doi.org/10.1002/hyp.9527

Liu XM, Liu CM, Brutsaert W (2016) Regional evaporation estimates in the eastern monsoon region of China: Assessment

Liu Z, Yao Z, Wang R (2019) Simulation and evaluation of actual evapotranspiration based on inverse hydrological modeling at a basin scale. Catena 180:160-168. https://doi.org/10.1016/j.catena.2019.03.039

Li Z, Chen YN, Yang J, Wang Y (2014) Potential evapotranspiration and its attribution over the past 50 years in the arid 518 region of Northwest China. Hydrol Process 28:1025-1031. https://doi.org/10.1016/10.1002/hyp.9643

519 Ma N, Szilagyi J (2019) The CR of evaporation: A calibration-free diagnostic and benchmarking tool for large-scale terrestrial evapotranspiration modeling. Water Resour Res 55:7246-7274. https://doi.org/10.1029/2019WR024867

Maes WH, Steppe K (2012) Estimating evapotranspiration and drought stress with ground-based thermal remote sensing in agriculture: a review. J Exp Bot 63:4671-4712. https://doi.org/10.1093/jxb/ers165

Masson V, Champeaux JL, Chauvin F, Meriguet C, Lacaze R (2003) A global database of land surface parameters at 1km resolution in meteorological and climate models. J Clim 9:1261-1282. https://doi.org/10.1175/1520-044216.9.1261 
McMahon TA, Peel MC, Lowe L, Srikanthan R, McVicar TR (2013) Estimating actual, potential, reference crop and pan evaporation using standard meteorological data: A pragmatic synthesis, Hydrol Earth Syst Sci 17:1331-1363. https://doi.org/10.5194/hess-17-4503-2013

Moratiel R, Duran JM, Snyder RL (2010) Responses of reference evapotranspiration to changes in atmospheric humidity and air temperature in Spain. Clim Res 44:27-40. https://doi.org/ 10.3354/cr00919

Morton FI (1983) Operational estimates of areal evapotranspiration and their significance to the science and practice of

534 hydrology. J Hydrol 66:1-76. https://doi.org/10.1016/0022-1694(83)90177-4

535 Nakamichi T, Moroizumi T (2015) Applicability of three complementary relationship models for estimating actual 536 evapotranspiration in urban area. J Hydrol Hydromechanics 63:117-123. https://doi.org/10.1515/johh-2015-0011

537 Oki T, Kanae S (2006) Global hydrological cycles and world water resources. Science 313:1068-1072. 538 https://doi.org/10.1126/science.1128845

539 Penman HL (1948) Natural evaporation from open water, bare soil and grass. Proc R Soc Lond A Math Phys Sci 193:120540 145. https://doi.org/10.1098/rspa.1948.0037

541 Priestley CHB, Taylor RJ (1972) On the assessment of surface heat flux and evaporation using large-scale parameters. 542 Mon Weather Rev 100:81-92. https://doi.org/10.1175/1520-0493(1972)1002.3.CO;2

543 Sabo JL, Ruhi A, Holtgrieve GW, Elliott V, Arias ME, Ngor PB, Rasanen TA, Nam S (2017) Designing river flows to 544 improve food security futures in the Lower Mekong Basin. Science 358: eaao1053. $545 \quad$ https://doi.org/10.1126/science.aao1053

546 Szilagyi J (2007) On the inherent asymmetric nature of the complementary relationship of evaporation. Geophys Res Lett 547 34:L02405. https://doi.org/10.1029/2006GL028708

548 Szilagyi J, Crago R, Qualls R (2017) A calibration-free formulation of the complementary relationship of evaporation for 549 continental-scale hydrology. J Geophys Res 122:264-278. https://doi.org/ 10.1002/2016JD025611

550 Szilagyi J, Hobbins MT, Jozsa J (2009) Modified advection-aridity model of evapotranspiration. J Hydrol Eng 14:569551 574. https://doi.org/10.1061/(ASCE)HE.1943-5584.0000026

552 Trenberth KE, Fasullo JT, Kiehl J (2009) Earth's global energy budget. Bull AM Meteorol Soc 90:311-323. 553 https://doi.org/10.1175/2008BAMS2634.1 
554 Valipour M (2015) Importance of solar radiation, temperature, relative humidity, and wind speed for calculation of

555 reference evapotranspiration. Arch Agron Soil Sci 61:239-255. https://doi.org/10.1080/03650340.2014.925107

556 Wan ZM, Zhang K, Xue XW, Hong Z, Hong Y, Gourley JJ (2015) Water balance based actual evapotranspiration

557 reconstruction from ground and satellite observations over the Conterminous United States. Water Resour Res

558 51:6485-6499. https://doi.org/10.1002/2015WR017311

559 Xu CY, Singh VP (2005) Evaluation of three complementary relationship evapotranspiration models by water balance

560 approach to estimate actual regional evapotranspiration in different climatic regions. J Hydrol 308:104-121.

$561 \quad$ https://doi.org/10.1016/j.jhydrol.2004.10.024

562 Xu RR, Gao P, Mu XM, Gu CJ (2021) Spatial-temporal change of actual evapotranspiration and the causes based on the

563 advection-aridity model in the Weihe River basin, China. Water 13:303. https://doi.org/10.3390/w13030303

564 Yang JH, Wang W, Hua TT, Peng M (2021) Spatiotemporal variation of actual evapotranspiration and its response to

565 changes of major meteorological factors over China using multi-source data. J Water Clim Change 12:325-338.

566 https://doi.org/10.2166/wcc.2020.221

567 Zhang L, Cheng L, Brutsaert W (2017) Estimation of land surface evaporation using a generalized nonlinear 568 complementary relationship. J Geophys Res 122:1475-1487. https://doi.org/ 10.1002/2016JD025936

569 Zhang YQ, Leuning R, Chiew FHS, Wang EL, Zhang L, Liu CM, Sun FB, Peel MC, Shen YJ, Jung M (2012) Decadal

570 trends in evaporation from global energy and water balances. J Hydrometeorol 13:379-391.

$571 \quad$ https://doi.org/10.1175/JHM-D-11-012.1

572 Zhou HX, Han SJ, Liu WZ (2020) Evaluation of two generalized complementary functions for annual evaporation 573 estimation on the Loess Plateau, China. J Hydrol 587:124980. https://doi.org/10.1016/j.jhydrol.2020.124980 